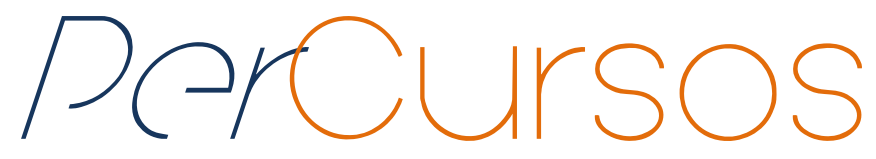

\title{
Ciberespaço e território: construção de uma discussão interdisciplinar
}

\section{Resumo}

As Tecnologias de Informação e Comunicação podem ser analisadas como elementos importantes para a compreensão de questões relativas à sociedade e à cultura no século XXI, podendo ser consideradas ferramentas utilizadas pela humanidade na busca pelo atendimento às suas necessidades. Adotando o conceito de ciberespaço proposto por Pierre Lévy, este artigo assumiu uma abordagem interdisciplinar ao relacionar os campos da Ciência da Informação e da Geografia. Por um lado, questões como mobilidade e fronteiras são temas da Geografia que passam a ser utilizados em relação à informação. Por outro lado, a evolução das Tecnologias da Informação e da Comunicação remete a novas perspectivas em relação aos conceitos de espaço e território, requeridos para descrever a realidade do mundo globalizado e dos sujeitos "em rede". O campo dos estudos territoriais traz recursos teóricos para a efetivação dessas análises. Assim, o ciberespaço, fruto da interconexão mundial dos computadores, pode constituir um novo território que não se define apenas pela infraestrutura material dos processos de telecomunicação, mas também pela forma como as pessoas se relacionam e trocam informações.

Palavras-chave: Cibercultura; Ciberespaço; Território.

\author{
Maria Gabriela Parenti Bicalho \\ Doutora em Educação pela \\ Universidade Federal de Minas \\ Gerais - UFMG. Professora da \\ Universidade \\ Federal de Juiz de Fora - UFJF. \\ Brasil \\ gpbicalho1@uol.com.br
}

\section{Rossana Cristina Ribeiro Morais Mestre em Gestão Integrada do Território pela Universidade Vale do Rio Doce - UNIVALE. \\ Brasil \\ rossanacrm73@gmail.com}

\section{Para citar este artigo: \\ BICALHO, Maria Gabriela Parenti; MORAIS, Rossana Cristina Ribeiro. Ciberespaço e território: construção de uma discussão interdisciplinar. Revista PerCursos, Florianópolis, v. 17, n.34, p. 05 - 23, maio/ago. 2016.}

DOI: 10.5965/1984724617342016005

http://dx.doi.org/10.5965/1984724617342016005 


\title{
Cyberspace and territory: construction of an interdisciplinary discussion
}

\begin{abstract}
Information and communication technologies can be considered as important elements for the understanding of issues related to society and culture in the twenty-first century, it may be considered tools used by mankind in pursuit of reaching their needs. Adopting the concept of cyberspace proposed by Pierre Lévy, this article takes an interdisciplinary approach relating the fields of Computer Science and Geography. On one hand, issues such as mobility and borders are subjects of geography that are now used in relation to information. On the other hand, the evolution of information technology and communication technologies refer to new perspectives on the concepts of space and territory, required to describe the reality of the globalized world and individuals "in the network." The field of territorial studies brings theoretical resources for the realization of these analyzes. Thus, cyberspace, due to the global interconnection of computers, may constitute a new territory that is not defined only by the physical infrastructure of telecommunications processes, but also the way people interact and exchange information.
\end{abstract}

Keywords: Cyberculture; Cyberspace; Territory. 


\section{Introdução}

As implicações da evolução das Tecnologias de Informação e Comunicação (TICs) sobre a organização social constituem objeto de estudo e pesquisa de diversas disciplinas e são estudadas a partir de diferentes pontos de vista. Neste trabalho, discutimos essas implicações sobre a relação da sociedade com o espaço, a partir de leitura interdisciplinar dos campos da Ciência da Informação e da Geografia, relacionando os conceitos de ciberespaço e cibercultura aos conceitos de desterritorialização e reterritorialização.

Em tal perspectiva, as novas Tecnologias de Informação e Comunicação são consideradas ferramentas utilizadas pela humanidade em suas relações em e com o território, e conceitos dos estudos territoriais proporcionam elementos para compreensão das transformações sociais no contexto da evolução dessas tecnologias.

2. Ciberespaço e cibercultura: buscas de compreensão da contemporaneidade

Castells (1999)atribui à contemporaneidade a vivência de uma revolução tecnológica caracterizada por conectividade, ubiquidade e instantaneidade, que tem como princípios de transformação as Tecnologias da Informação, de processamento e da comunicação. Nessa revolução, os conhecimentos e a informação são aplicados na "geração de conhecimentos e dispositivos de processamento/comunicação da informação, em um ciclo de realimentação cumulativo entre a inovação e seu uso." (CASTELLS, 1999, p. 69). O autor identifica, a partir da revolução tecnológica, a formação de um novo sistema de comunicação que fala uma língua "universal digital”, promove a "integração global da produção e distribuição de palavras, sons e imagens de nossa cultura" e conduz a uma modificação substancial das formas sociais de espaço e tempo (CASTELLS, 1999, p. 40).

É importante salientar que esta revolução tecnológica teve influência direta na Ciência da Informação, pois, segundo Barreto (2007), aspectos como condição da informação e suas possibilidades de distribuição foram alterados a partir do uso de novas 
tecnologias. Bembem (2013) também destaca que a evolução da Ciência da Informação está diretamente relacionada ao desenvolvimento tecnológico.

O conceito de Ciência da Informação surgiu como resultado das conferências do Georgia Institute of Technology e foi definido, conforme apresenta Souza (2007), como ciência que investiga " [...] ]as propriedades e o comportamento da informação, as forças que governam o fluxo da informação e os meios de processamento da informação para um máximo de acessibilidade e uso." Os processos investigados por essa ciência incluem a "geração, disseminação, coleta, organização, armazenamento, recuperação, interpretação e uso da informação." (SOUZA, 2007, p.76)

Para a autora,

a Ciência da Informação combina o entendimento da Tecnologia da Informação com o estudo científico do comportamento humano em sua busca de informação e o modo de processá-la, bem como a forma de utilizar efetivamente o potencial de armazenamento, organização e manipulação de dados proporcionados pelo computador.(SOUZA, 2007, p. 70)

Barreto (2002; 2007; 2009) divide a Ciência da Informação em três tempos distintos: tempo gerência da informação de 1945 - 1980; tempo relação informação e conhecimento de 1980 - 1995; e tempo do conhecimento interativo a partir de 1995. O tempo da gerência tinha como foco a organização, ordenação e o controle da informação. No tempo da relação informação e conhecimento, o foco era a transformação da informação em conhecimento. Já no tempo do conhecimento interativo, tanto a informação quanto a comunicação sofrem alteração por meio do uso de novas tecnologias. É importante destacar que essas características não são excludentes, apenas definem as características principais de cada período.

O autor também destaca que as tecnologias possibilitaram "uma nova forma de lidar com o acesso à informação e às modificações relacionadas ao tempo e ao espaço de sua transferência." (BARRETO, 2007, p.13). Essa ideia nos aproxima de nosso objeto de análise neste trabalho ao mostrar as relações entre a Ciência da Informação e a Geografia. 
Nessa abordagem interdisciplinar, a tecnologia desenvolve-se dentro de uma cultura em uma dada sociedade, portanto, pode ser considerada fator condicionante - e não determinante - da vida social, possibilitando novas perspectivas de ações culturais e sociais. O desenvolvimento tecnológico está vinculado às formas como os atores humanos inventam, produzem, utilizam e interpretam as técnicas. Castells (1999, p. 62), fazendo referência ao historiador Fernand Braudel, afirma que "a tecnologia não determina a sociedade: incorpora-a. Mas a sociedade também não determina a tecnologia: utiliza-a". O autor destaca que

Embora não determine a evolução histórica e a transformação social, a tecnologia (ou a sua falta) incorpora a capacidade de transformação das sociedades, bem como os usos que as sociedades, sempre em um processo conflituoso, decidem dar ao seu potencial tecnológico. (CASTELLS, 1999, p. 44-45)

Nessa ótica, pode-se pensar que processos sociais e transformação tecnológica resultam de uma interação complexa em que fatores sociais pré-existentes afetam o avanço tecnológico e suas aplicações sociais (CASTELLS,1999).

Nesse contexto, o ciberespaço se apresenta como espaço no qual as informações digitais circulam, permitindo às pessoas a construção e partilha de inteligência coletiva. Pierre Lévy (1999) o define como espaço de comunicação aberto pela interconexão mundial dos computadores e das memórias dos computadores, que tende a tornar-se a principal infraestrutura de produção, transação e gerenciamento econômicos. Também chamado de rede, não é apenas a infraestrutura material de comunicação digital, mas constitui um "universo oceânico de informações que ela abriga, assim como os seres humanos que navegam e alimentam esse universo." (LÉVY, 1999, p. 17).No ciberespaço estruturam-se, segundo o autor, relações sociais, econômicas e de poder e ocorre o crescimento da mobilidade de acesso às informações e das possibilidades de interação.

O acesso ao ciberespaço é feito por meio de módulos de processamento, como computadores pessoais, celulares, tablets, notebooks, entre outros, que deixam de ser um centro e passam a ser um nó de uma grande rede universal, sendo impossível traçar 
os limites e as possibilidades de acesso ao conteúdo deste espaço onde se estruturam novas relações sociais, econômicas e de poder. Encoraja, portanto, um estilo de relacionamento quase independente dos lugares geográficos e da coincidência dos tempos, constituindo um território que não se define apenas pela infraestrutura material dos processos de telecomunicação, mas também pela forma como as pessoas se relacionam e trocam informações (LÉVY, 1999; BARRETO, 2007).

Sobre isso, Barreto (2002) afirma que

\begin{abstract}
A assimilação da informação no ciberespaço acontece em um ponto do presente que se repete cotidianamente ao infinito; ainda que conservando a qualidade das vivências do passado e o sonho do futuro. $O$ ponto de apropriação da informação e do conhecimento tem no presente sua única dimensão do tempo. (BARRETO, 2002).
\end{abstract}

Quanto mais o ciberespaço cresce, mais ele se torna universal, o que não significa a totalidade do mundo informacional. Lévy (1999) destaca que a universalidade do ciberespaço não pode ser considera neutra, tendo em vista o fato de que a interconexão permite o contato entre pontos quaisquer, podendo ter uma repercussão em diversas atividades da sociedade, como as atividades econômicas, políticas e culturais.

O ciberespaço pode ser visto como "prática de comunicação interativa, recíproca, comunitária e intercomunitária, [...] como horizonte de mundo virtual vivo, heterogêneo e intotalizável do qual cada ser humano pode participar e contribuir."(LÉVY, 1999, p. 126).

Por meio da interação proporcionada pelo ciberespaço, os usuários da informação podem explorar e atualizar os mundos virtuais. A interação permite uma participação ativa e possibilita uma intervenção direta no fluxo informacional, possibilitando interrompê-lo e reorientá-lo em tempo real, transformando, segundo Lévy (1999), o mundo virtual em um vetor de inteligência e criação coletivas. Nesse sentido, Barreto (2009) renomeia o tempo de conhecimento interativo como tempo do ciberespaço. Entre as características desse tempo, destacam-se a cooperação, a interatividade, a instantaneidade e o compartilhamento, possibilitados pelo uso das tecnologias. 
O ciberespaço tende a crescer, cada vez mais, em interconexão, em integração, e em sistemas independentes, universais e “transparentes”. Para Lévy (1999),

O movimento social e cultural que o ciberespaço propaga, um movimento potente e cada vez mais vigoroso, não converge sobre um conteúdo particular, mas sobre uma forma de comunicação não midiática, interativa, comunitária, transversal, rizomática. (LÉVY, 1999, p.132)

Vinculada a este espaço de comunicação, no qual as atividades humanas implicam sempre na interação entre pessoas, máquinas e ideias, está a cibercultura, que é definida por Lévy (1999, p.17) como “o conjunto de técnicas (materiais e intelectuais), de práticas, de atitudes, de modos de pensamento, de valores que se desenvolvem juntamente com o crescimento do ciberespaço". Ela é universal, aberta, formada por redes que não se circunscrevem em uma totalidade. A interconexão possibilita a compatibilidade, a interoperabilidade e permite o acesso às comunidades virtuais e seus conteúdos, possibilitando o desenvolvimento da inteligência coletiva. Isso constitui o universal. Entretanto, a interconexão de todos com todos possibilitando uma comunicação interativa, permite pensar que não será possível chegar a uma totalização, pois sempre existirão novas linhas de fuga, fontes sempre mais heterogêneas e novos dispositivos de comunicação (LÉVY, 1999). Pode-se considerar, segundo o autor, que o ciberespaço é um espaço virtual no qual são formados grupos, comunidades, redes de aprendizagem, de relacionamento e que a informação está virtualmente presente em cada ponto em que for solicitada, entendendo aqui que o virtual irá possibilitar novas oportunidades de atualizar o real e não substituí-lo.

O crescimento do ciberespaço e, consequentemente, da cibercultura é orientado por três aspectos: a interconexão, a criação de comunidades virtuais e a inteligência coletiva. Esses fatores são, portanto, condições necessárias para o crescimento universal do ciberespaço. 
Não há comunidade virtual sem interconexão, não há inteligência coletiva em grande escala sem a virtualização ou desterritorialização das comunidades no ciberespaço. A interconexão condiciona a comunidade virtual, que é uma inteligência coletiva em potencial. (LÉVY, 1999, p.133)

A interconexão é a comunicação universal de todos os equipamentos conectados na rede, a qual "constitui a humanidade em um contínuo sem fronteiras [...] [e] tece um universal por contato". O autor afirma que as comunidades virtuais "realizam de fato uma verdadeira atualização (no sentido da criação de um contato efetivo) de grupos humanos que eram apenas potenciais antes do surgimento do ciberespaço." (LÉVY, 1999, p. 127-130). A formação da inteligência coletiva depende, como mostra a citação anterior, da virtualização, que o autor denomina desterritorialização das comunidades. Ele adota o termo "nomadismo" para tratar da “[...] transformação contínua e rápida das paisagens científica, técnica, econômica, profissional, mental.”(LÉVY, 2003, p. 14). O movimento humano não é mais deslocar-se de um ponto a outro na superfície terrestre, mas "atravessar universos de problemas, mundos vividos, paisagens dos sentidos. [...] Somos imigrantes da subjetividade." (LÉVY, 2003, p. 14).

Voltamos, assim, à ideia de Castells (1999) a respeito da modificação das formas sociais de espaço e tempo promovidas pela revolução tecnológica. Conceitos ligados à vivência territorial, como limites, fronteiras e deslocamento reconfiguram-se na vivência do ciberespaço por sujeitos em rede.

Essa imbricação já se faz presente no próprio termo ciberespaço e fundamenta a proposta deste trabalho de aportar à discussão dessa realidade conceitos do campo da Geografia.

\section{Ciberespaço e cibercultura como processos de desterritorialização,}

\section{reterrirorialização e multiterritorialidade}

Os conceitos de desterritorialização, reterritorialização e multiterritorialidade compõem os estudos territoriais, campo da Geografia que discute Território como ideia central de compreensão da ação humana. O conceito de Território possui dupla 
conotação, uma no sentido material e outra no sentido simbólico, inspirando a identificação e a efetiva apropriação, simultaneamente, conforme afirma Haesbaert (2005). Território tem a ver com poder, tanto no sentido político, mais concreto, de dominação, quanto no sentido simbólico, de apropriação (HAESBAERT, 2010). Ele pode se definir por sua materialidade, pelas relações de poder, pelas bases de produção, pela dimensão simbólica, pelas intervenções sociais e pela construção da subjetividade ou identidade pessoal.

Para explicar o funcionamento do mundo atual, Santos (1994) propõe que o espaço geográfico socialmente organizado, sinônimo de território usado, seja compreendido como mediação entre o mundo e a sociedade nacional e local. Ao apresentar esta proposta, o autor amplia a discussão para além da concepção restrita ao Estado-Nação e destaca o uso e o controle social cristalizado no território, que atualmente pode ser formado de lugares contíguos e de lugares em rede. Para Santos (1994), as redes constituem uma realidade nova, mas para além delas, existe o espaço de todos e todo o espaço. Esse espaço geográfico também se refere aos fluxos, aos movimentos, à circulação de mercadorias, de pessoas e de ideias (SANTOS, 1988).

Na perspectiva de Hasbaert (2010), o conceito de território é bastante amplo, “pois envolve as múltiplas formas de apropriação do espaço, nas diversas escalas espaçotemporais", não necessariamente sob uma perspectiva rígida da estabilidade, mas inclusive a partir das mobilidades geradas nos grupos sociais pelos desenvolvimentos tecnológicos. Lemos (2006) define território através da ideia de controle sobre fronteiras, podendo essas ser físicas, sociais, simbólicas, culturais, subjetivas. Para o autor, criar um território significa, além de dominar movimentos que se dão no interior de suas fronteiras, apropriar-se física e simbolicamente dos vários elementos da vida.

Ao tomar o conceito de Território, procura-se contemplar e permitir a análise dos movimentos humanos, permanentes, de desterritorialização e reterritorialização.

Ao serem abordados esses conceitos, recorre-se aos filósofos franceses Deleuze e Guattari. Em entrevista, Deleuze afirma: 
[...] construímos um conceito de que gosto muito, o da desterritorialização. [...] precisamos às vezes inventar uma palavra bárbara para dar conta de uma noção com pretensão nova. A noção com pretensão nova é que não há território sem um vetor de saída do território, e não há saída do território, ou seja, desterritorialização, sem, ao mesmo tempo, um esforço para se reterritorializar em outra parte. (DELEUZE no vídeo "L’abécédaire de Gilles Deleuze", filmado em 1988 por Claire Parnet, apud HAESBAERT, 2010, p.99).

Deleuze e Guattari (1972; 2009) desenvolvem esses conceitos e constroem a ideia de que os territórios sempre comportam dentro de si vetores de desterritorialização e de reterritorialização.

Ao adotar essa perspectiva em nossa análise, pretendemos "[...] operar por deslocamentos. Tomar conceitos de Deleuze e deslocá-los para o campo, para o plano da imanência que é a educação." (GALLO, 2008, p.54, grifo do autor). Assim, esses conceitos passam a ser dispositivos, agenciamentos, intercessores para pensar as transformações da Ciência da Informação, "dispositivos para produzir diferenças e diferenciações no plano educacional [...] uma abertura de possibilidades, incitação, incentivo à criação." (GALLO, 2008, p.54).

Para Deleuze e Guattari (1992), território é um conceito fundamental da filosofia. Para Guattari e Rolnik (2010), a noção de território

é entendida num sentido muito amplo, que ultrapassa o uso que fazem dele a etologia e a etnologia. Os seres existentes se organizam segundo territórios que se delimitam e os articulam aos outros existentes e aos fluxos cósmicos. O território pode ser relativo tanto a um espaço vivido, quanto a um sistema percebido no seio do qual um sujeito se sente "em casa”. O território é sinônimo de apropriação, de subjetivação fechada sobre si mesma. Ele é o conjunto de projetos e representações nos quais vai desembocar, pragmaticamente, toda série de comportamentos, de investimentos, nos tempos e nos espaços sociais, culturais, estéticos, cognitivos. (GUATTARI;ROLNIK, 2010, p.388)

Guatarri e Rolnik (2010) apontam o território como sinônimo de apropriação, de subjetivação, sendo que 
O território pode se desterritorializar, isto é, abrir-se, engajar-se em linhas de fuga e até sair do seu curso e se destruir. A espécie humana está mergulhada num imenso movimento de desterritorialização, no sentido de que seus territórios "originais" se desfazem ininterruptamente com a divisão social do trabalho, com a ação dos deuses universais que ultrapassam os quadros da tribo e da etnia, com os sistemas maquínicos que a levam a atravessar cada vez mais rapidamente, as estratificações materiais e mentais. (GUATTARI; ROLNIK, 2010, p.388)

A desterritorialização e a reterritorialização são processos indissociáveis. Se há um movimento de desterritorialização, haverá também um movimento de reterritorialização, podendo-se afirmar que eles são concomitantes. "Temos que pensar a desterritorialização como uma potência perfeitamente positiva, que possui seus graus e seus limiares e que sempre é relativa, tendo, em reverso, uma complementaridade na reterritorialização.” (DELEUZE; GUATTARI, 2009, p.69).

Nesse contexto, a vida é um constante movimento de desterritorialização/reterritorialização. Estamos sempre passando de um território a outro, abandonando territórios, criando novos territórios. Trata-se de uma desterritorialização/reterritorialização cotidiana, em que se abandona o território, mas não se destrói o território abandonado (HAESBAERT, 2010). “A reterritorialização consistirá numa tentativa de recomposição de um território engajado num processo desterritorializante." (GUATTARI; ROLNIK, 2010, p.388).

Para Haesbaert (2010), pode-se afirmar que a desterritorialização é o movimento de abandono do território, e a reterritorialização é o movimento de construção do território.

Neste trabalho, esses conceitos foram relacionados à discussão do ciberespaço, considerando que a interconexão interativa comporta fontes sempre heterogêneas, os dispositivos se modificam continuamente "as linhas de fuga irão multiplicar-se."(LEVY, 1999, p. 133). Lemos (2006) afirma que a internet

É efetivamente, máquina desterritorializante sob os aspectos político (acesso e ação além de fronteiras), econômico (circulação financeira 
mundial), cultural (consumo de bens simbólicos mundiais) e subjetivo (influência global na formação do sujeito). Estão em marcha processos de desencaixe e de compressão espaço-tempo na cibercultura. (LEMOS, 2006, p. 6)

Ainda para o autor, o ciberespaço proporciona a criação de linhas de fuga e desterritorializações, assim como reterritorializações. Alguns recursos existentes no ciberespaço possibilitam o compartilhamento de informação e a integração, que agora possuem um caráter dinâmico e aberto. A multiplicidade da rede proporciona uma articulação transversal, em rizoma, sem unificação sobrejacente e cada ponto desta rede, cada indivíduo, cada grupo pode ser um emissor de informação (LÉVY, 1999).

O termo rizoma, utilizado por Deleuze e Guattari (1995) para traduzir o conceito de multiplicidade, tem origem na botânica e, conforme o Dicionário Aurélio (1988), significa caule longo, horizontal e subterrâneo. No dicionário Michaelis (1998), o termo está definido como "ri.zo.ma sm Bot (rizo+oma) - Caule subterrâneo no todo ou em parte e de crescimento horizontal". Essas definições mostram que o rizoma está ligado a um crescimento horizontal. O rizoma, de acordo com Deleuze e Guattari (1995), é regido por seis princípios básicos:

$1^{\circ}$ e $2^{\circ}$ - Princípios de conexão e de heterogeneidade: Qualquer ponto do rizoma pode ser conectado com qualquer outro e deve sê-lo. $3^{\circ}$ - Princípio da multiplicidade: Uma multiplicidade não tem nem sujeito nem objeto, mas somente determinações, grandezas, dimensões que não podem crescer sem que ela mude de natureza - as leis de combinação aumentam, pois, com a multiplicidade. $4^{\circ}$ - Princípio da ruptura asignificante: Um rizoma pode ser rompido, quebrado em lugar qualquer, e também retorna segundo uma ou outra de suas linhas e segundo outras linhas. $5^{\circ}$ e $6^{\circ}$ - Princípio da cartografia e da decalcomania: "Um rizoma não pode ser justificado por nenhum modelo estrutural ou gerativo. [...] Uma das características mais importantes do rizoma talvez seja a de ter sempre múltiplas entradas. (DELEUZE; GUATTARI, 1995, p. 22-30)

Percebe-se, então, uma grande semelhança entre o conceito de rizoma e a complexidade do ciberespaço, pois, assim como o rizoma descrito por Deleuze e Guattari, 
o ciberespaço também é descentralizado, cada nó tem sua capacidade de criar novas conexões e ele se transforma a cada momento. Lemos (1996) destaca que

é óbvia a semelhança entre as estruturas rizomáticas e o cyberespaço. Ambos são descentralizados, conectando pontos ordinários, criando territorialização e desterritorialização sucessivas. O cyberespaço não tem um controle centralizado, multiplicando-se de forma anárquica e extensa, desordenadamente, a partir de conexões múltiplas e diferenciadas. (LEMOS, 1996, p.11-12)

Essa descentralização do ciberespaço é reforçada por Lévy (1993) quando apresenta o princípio da mobilidade dos centros:

a rede não tem centro, ou melhor, possui permanentemente diversos centros que são como pontas luminosas perpetuamente móveis, saltando de um nó a outro, trazendo ao redor de si uma ramificação infinita de pequenas raízes, de rizomas, finas linhas brancas esboçando por um instante um mapa qualquer com detalhes delicados, e depois correndo para desenhar mais à frente outras paisagens de sentido. (LÉVY, 1993, p. 26)

Para o autor, o computador deixa de ser um centro, para ser um elemento da “rede universal calculante”, relacionado a todos os elementos do “tecno-cosmo”(LÉVY, 1999). Para ele:

No limite, há apenas um único computador, mas é impossível traçar seus limites, definir seu contorno. É um computador cujo centro está em toda parte e a circunferência em lugar algum, um computador hipertextual, disperso, vivo, fervilhante, inacabado: o ciberespaço em si. (LÉVY, 1999, p. 44)

Nesse contexto, o ciberespaço pensado como um território que se apresenta de forma descontínua, móvel e espacialmente fragmentado, território-rede, e as novas perspectivas espaço-temporais proporcionadas pelo desenvolvimento tecnológico, 
remetem-nos a uma nova forma de controle do espaço de reprodução social. $\mathrm{Na}$ sociedade dita pós-moderna, o "viver em rede" sobrepõe o controle e a definição de “fronteira", e a mobilidade é fator importante. (HAESBAERT, 2010)

A estrutura de uma sociedade em rede, conforme destaca Haesbaert (2010), pode significar novas territorializações e a própria rede, na dinâmica da sociedade pósmoderna, torna-se um território. As sociedades contemporâneas, configurando territórios descontínuos, fragmentados e superpostos, podem ser pensadas como processos de territorialização, uma vez que segundo Haesbaert (2010, p. 280), “territorializar-se significa também, hoje, construir e/ou controlar fluxos/redes e criar referenciais simbólicos num espaço em movimento, no e pelo movimento."

Entende-se, assim, que as principais transformações sociais promovidas pela revolução tecnológica podem ser analisadas sob a ótica da relação entre tempo e espaço, alterada pelas comunicações em redes de alcance mundial. O ciberespaço permite a comunicação de todos com todos independente de espaços físicos, permite também que o usuário deste território virtual vivencie processos que não fazem parte de sua tradição cultural. A ligação entre ciberespaço e território pode ser desenvolvida a partir da discussão de Castells (1999). Para o autor,o novo meio de comunicação, por meio da sua diversificação, multimodalidade e versatilidade, é capaz de incluir e abranger todas as expressões culturais. As experiências humanas de percepção e criação simbólicas podem ser transformadas pela característica multimídia das novas tecnologias. Nesse sentido, Castells (1999) destaca que o novo sistema tecnológico pode alterar de forma fundamental a cultura, uma vez que ela é determinada e mediada pela comunicação.

Para Haesbaert (2010, p. 205),

o ciberespaço é central tanto na compreensão da fluidez financeira e da fragilização das fronteiras quanto da aceleração dos processos de 'hibridização' cultural. Tendo o cuidado de não cair num determinismo tecnológico, é indispensável reconhecer o papel crescente das tecnologias informacionais nos processos de desterritorialização. (HAESBAERT, 2010, p 205) 
Pode-se entender, então, que os processos de desterritorialização estão ligados ao aumento da mobilidade, seja de pessoas, de bens materiais, de capital ou de informação e que a dinâmica e a fluidez provocadas por esse processo podem ser vinculadas ao enfraquecimento ou diminuição do controle das fronteiras. Dessa forma, a possibilidade de interconexão de todos com todos proporcionada pelo ciberespaço, bem como o aumento da velocidade de transmissão das redes, vem apagando as fronteiras, encurtando as distâncias geográficas e gerando processos de desterritorialização, reterritorialização e multiterritorialidade.

O ciberespaço está relacionado às atividades espontâneas, descentralizadas e participativas, e a "cada conexão suplementar acrescenta ainda heterogeneidade, novas fontes de informação, novas linhas de fuga, a tal ponto que o sentido global encontra-se cada vez menos perceptível, cada vez mais difícil de circunscrever, de fechar, de dominar." (LEVY, 1999, p. 120)

Haesbaert (2010) aponta que

uma das principais modalidades da virtualização é, assim, "o desprendimento do aqui e agora", ou seja, "o virtual, com frequência, não está presente", o que provoca constantes confusões entre virtual e "irreal". Isto significa [...], que a virtualização e o ciberespaço são os melhores exemplos da compressão ou do desencaixe tempo-espaço em que vivemos. [...], esses processos vinculados à presença-ausência, são apenas uma das diferentes características ou formas de manifestação da dinâmica de desterritorialização. (HAESBAERT, 2010, p.272)

Lemos (2006) destaca o aspecto desterritorializante do ciberespaço e, assim como Haesbaert (2010), alerta que todo processo de desterritorialização vem acompanhado de reterritorialização. Além disso, "não devemos compreender o ciberespaço como um espaço liso, ou apenas como um espaço de desencaixe e de compressão espaço-tempo, mas como lugar de quebra e criação de controle e de hierarquias, de territorialização e desterritorialização." (LEMOS, 2006, p.7)

As redes contemporâneas, configurando territórios descontínuos, fragmentados e superpostos, podem ser pensadas como processos de territorialização, uma vez que 
segundo Haesbaert (2010, p. 280), “territorializar-se significa também, hoje, construir e/ou controlar fluxos/redes e criar referenciais simbólicos num espaço em movimento, no e pelo movimento."

A partir dessa discussão, Haesbaert (2010) propõe a noção de multiterritorialidade, admitida pela lógica descontínua dos territórios-rede. Essa noção refere-se à possibilidade de acessar diversos territórios, tanto no sentido físico quanto no virtual, inclusive com novas experiências espaço-temporais relacionadas ao uso do ciberespaço. Para o autor, a multiterritorialidade pode ser vista como consequência de relações sociais construídas por meio do território-rede e definida como uma reterritorialização complexa, não hierárquica, em rede e com conotações rizomáticas.

O ciberespaço permite, a todo instante, recombinar territórios em multiterritorialidades (HAESBAERT, 2010). O ciberespaço propicia a criação de zonas de significação móveis e mutáveis, que deverão ser devidamente apropriadas a cada navegação, pois, como alerta Lévy (1999), cada navegação pela imensa rede informacional é única. Os elementos do ciberespaço podem expressar desejos, ideias, saberes, transações. Por trás desses elementos "fervilham a multiplicidade e suas relações." (LEVY, 1999, p. 162)

Nesse sentido, Castells (1999) acredita que "entramos em um mundo realmente multicultural e interdependente, que só poderá ser entendido e transformado a partir de uma perspectiva múltipla que reúna identidade cultural, sistemas de redes globais e políticas multidimensionais." (CASTELLS, 1999, p. 62). O autor ainda destaca que em função das novas tecnologias de informação o mundo está sendo integrado em uma grande rede global de instrumentalidade, permitindo que seja gerada uma enorme quantidade de comunidades virtuais por meio da comunicação mediada por computadores.

Entende-se, assim, que as principais transformações sociais promovidas pela revolução tecnológica podem ser analisadas sob a ótica da relação entre tempo e espaço, alterada pelas comunicações em redes de alcance mundial. No sentido da compressão do espaço-tempo, o ciberespaço permite a comunicação de todos com todos independente 
de espaços físicos, enquanto o desencaixe permite que o usuário deste território virtual vivencie processos que não fazem parte de sua tradição cultural, um hibridismo cultural.

\section{Considerações Finais}

O desenvolvimento tecnológico trouxe novas possibilidades de conexão para a humanidade. Em consequência disso, pode-se observar uma diversificação nas relações de trabalho, na forma como as pessoas se relacionam, na forma de busca de conhecimento, entre outras. A relação da sociedade com o espaço se modifica a partir da evolução das Tecnologias de Informação e Comunicação (TICs) e, nesse contexto, a informação e o conhecimento constituem elementos-chave. A emergência do ciberespaço e todas as possibilidades de comunicação e interação proporcionadas por este meio podem impactar as formas de relacionamento e organização dos indivíduos na sociedade.O ciberespaço podeproporcionar uma transformação na comunicação e interação entre os usuários que fazem uso dos recursos permitidos por este ambiente, e a utilização desses recursos depende da apropriação do usuário a cada navegação, ou seja, o movimento social é quem produz e caracteriza o novo espaço resultante. Compreendese então, que os usuários, ao se apropriarem destas navegações, estão constituindo novos territórios. A territorialização nesses novos territórios não implica no abandono do território onde o sujeito está inserido. Nesse sentido, entende-se que pode haver desterritorialização e reterritorialização, e que, nesse movimento, ocorre a multiterritorialidade. O território anterior não é abandonado, mas pode ser ressignificado no novo território.

Os conceitos de territorialização, desterritorialização e multiterritorialidade constituem possibilidades de compreensão do ciberespaço e da cibercultura, pois admitem, mais do que outros conceitos, o movimento, a transformação permanente, a reconfiguração. O diálogo entre a Ciência da Informação e a Geografia pode, assim, gerar análises profícuas de diferentes aspectos das transformações sociais propiciadas pela evolução das Tecnologias de Informação e Comunicação. 


\section{Referências}

BARRETO, Aldo. A condição da informação. São Paulo em Perspectiva, v.6, n. 3, p. 67-74, 2002. Disponível em:<http://ridi.ibict.br/bitstream/123456789/173/1/BarretoS\%C3\%A30PauloemPerspectiva2002.pdf > . Acesso em: 04 de agosto de 2016.

BARRETO, Aldo. Uma história da Ciência da Informação. In: TOUTAIN, Lídia Maria Batista (Org.). Para entender a Ciência da Informação.Salvador: EDUFBA, 2007. p. 13 a 34. Disponível em:<http://tupi.fisica.ufmg.br/michel/docs/Artigos_e_textos/Ciencia_da_informacao/Para_entend er_a_Cl.pdf >. Acesso em: 04 de agosto de 2016.

BARRETO, Aldo. Os documentos de amanhã: a metáfora, a escrita e a leitura nas narrativas em formato digital. DataGramaZero, v. 10, n. 1., 2009. Disponível em <http://eprints.rclis.org/17653/1/Barreto-Art-v10n1-2009.pdf>. Acesso em: 04de agosto de 2016.

BEMBEM, Ângela Halen Claro. A Ciência da Informação e os espaços antropológicos: uma aproximação possível?. São Paulo: Fundação Editora da UNESP, 2013.

CASTELLS, Manuel. A sociedade em rede. São Paulo: Paz e Terra, 1999.

DELEUZE, Gilles; GUATTARI, Félix. Mil platôs: capitalismo e esquizofrenia, vol 1. Rio de Janeiro: Editora 34, 1995

DELEUZE, Gilles; GUATTARI, Félix. Mil platôs: capitalismo e esquizofrenia, v.1. $6^{\text {a }}$ reimp. São Paulo: Editora 34, 2009.

DELEUZE, Gilles; GUATTARI, Félix. O que é a filosofia? Lisboa: Presença, 1992.

FERREIRA, Aurélio Buarque de Holanda. Dicionário Aurélio Básico da Língua Portuguesa. Rio de Janeiro: Nova Fronteira, 1988.

GALLO, Sílvio. Deleuze \& a Educação. 2.ed. Belo Horizonte: Autêntica, 2008.

GUATTARI, Félix; ROLNIK, Suely. Micropolítica: cartografias do desejo. 10.ed. Petrópolis: Vozes, 2010.

HAESBAERT, Rogério. Da desterritorialização à Multiterritorialidade. Anais do X Encontro de Geógrafos da América Latina. São Paulo: USP, Departamento de Geografia, 20-26 de março de 2005.

HAESBAERT, Rogério. 0 mito da desterritorialização:do fim dos "territórios" à multiterritorialidade. 5 . ed. Rio de Janeiro: Bertrand Brasil, 2010. 
LEMOS, Andre. Ciberespaço e tecnologias móveis: processos de territorialização e desterritorialização na cibercultura. COMPÓs, 2006. Disponível em:<http://www.facom.ufba.br/ciberpesquisa/andrelemos/territorio.pdf >. Acesso em: 15 de maio de 2016.

LÉVY, Pierre. A inteligência coletiva. São Paulo: Edições Loyola, 2003.

LÉVY, Pierre. As tecnologias da inteligência. São Paulo: Editora 34, 1993;

LÉVY, Pierre. Cibercultura. São Paulo: Editora 34, 1999.

MICHAELIS: moderno dicionário da língua portuguesa. São Paulo: Companhia Melhoramentos, 1998.

SANTOS, Milton. Metamorfose do espaço habitado. São Paulo: Hucitec, 1988.

SANTOS, Milton. O Retorno do território. In: SANTOS, Milton. SOUZA, Maria Adélia A. e

SILVEIRA, Maria Laura (Org.). Território. globalização e fragmentação.São Paulo: Hucitec: ANPUR, 1994. p.15-20.

SOUZA, Maria da Paixão Neres . Abordagem inter e transdisciplinar. In: TOUTAIN, Lídia Maria Batista (Org.). Para entender a ciência da informação. Salvador: EDUFBA, 2007. p. 75-90.

Recebido em: 31/05/2016 Aprovado em: 24/08/2016

Universidade do Estado de Santa Catarina - UDESC Centro de Ciências Humanas e da Educação - FAED

Revista PerCursos

Volume 17 - Número 34 - Ano 2016 revistapercursos@gmail.com 